\title{
Intrathoracic kidney, dextroposition of the heart, right upper and middle lobe hypoplasia of lung and pulmonary hypertension
}

\author{
*Mohammed Abdul Wasiq ${ }^{1}$, J B K Prusty ${ }^{1}$, Anuspandana Mahapatra ${ }^{1}$, Mrutunjay Dash ${ }^{1}$ \\ Sri Lanka Journal of Child Health, 2021; 50(2): 350-352 \\ DOI: http://dx.doi.org/10.4038/sljch.v50i2.9587 \\ (Intrathoracic kidney, dextroposition of heart, pulmonary hypoplasia, mesonephros, metanephros)
}

\section{Introduction}

Intrathoracic kidney was first described by Campbell in $1930^{1}$. Intrathoracic kidneys constitutes less than $5 \%$ of all renal ectopias and have the lowest frequency rate in comparison to other forms of renal ectopias $^{2}$. We are describing a case report of intrathoracic kidney in a paediatric patient.

\section{Case report}

A male baby in his second month of life was brought to hospital with a respiratory tract infection of 4 days' duration. The child had noisy breathing and tachypnoea. The weight of the child was $3.85 \mathrm{~kg}$ with a birth weight of $2.2 \mathrm{~kg}$, suggestive of failure to thrive. The pulse rate was $146 /$ minute and the respiratory rate was $64 /$ minute. The child had retractions in the subcostal region with deviation of the mediastinum to the right. The breath sounds were well heard bilaterally and were of the vesicular type with rhonchi being present over both lung fields. The heart sounds were prominently heard over the right side of the chest with a systolic murmur best heard in the pulmonary area. Examination of the other systems was normal.

A provisional diagnosis of bronchiolitis was made and treatment was started while awaiting investigations. Chest $X$ ray (Figure 1) showed a white opacity in the right lung with shifting of mediastinum to the right side. The heart was dextroposed. Left lung was normal.

$\overline{{ }^{1} \text { Institute of Medical Sciences and SUM Hospital, }}$ Bhubaneswar, Odisha, India

*Correspondence:

mohammedwasiq03@gmail.com

https://orcid.org/0000-0002-8920-6819

(Keceived on 03 July 2020: Accepted after revision on 21 August 2020)

The authors declare that there are no conflicts of interest

Personal funding was used for the project.

Open Access Article published under the Creative

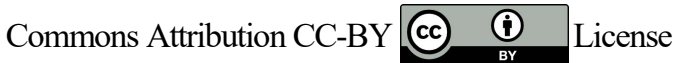

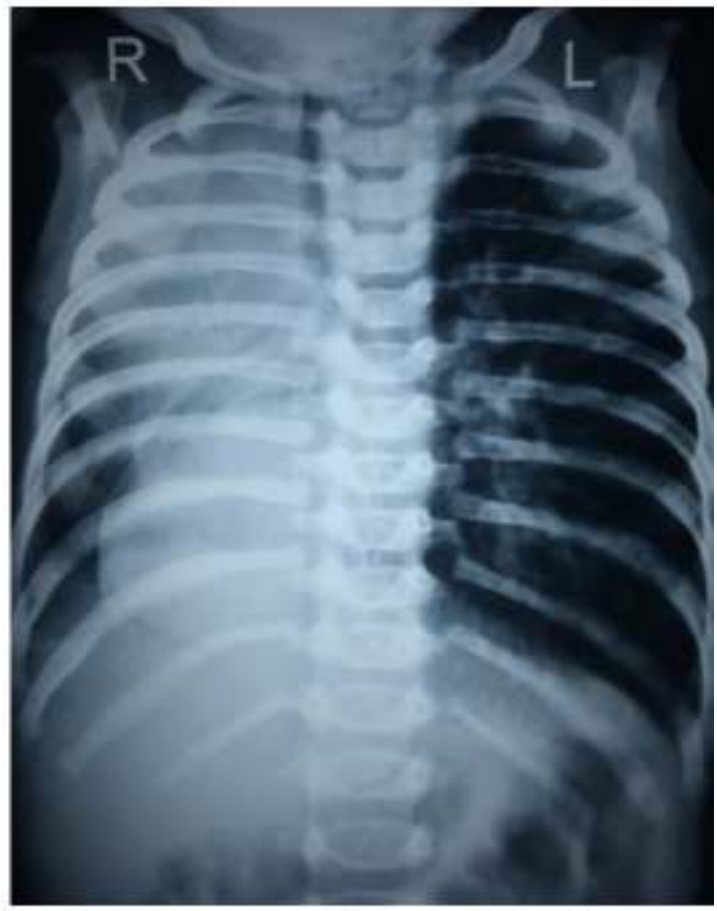

Figure 1: Chest $x$-ray showing white opacity in right lung with shifting of mediastinum to the right side

2D echocardiogram revealed dextroposed heart with sub-aortic ventricular septal defect (VSD), atrial septal defect (ASD) and severe pulmonary hypertension.

Contrast enhanced computed tomography (CECT) of thorax was suggestive of pulmonary hypoplasia of right upper and middle lobes of lung. The right kidney was herniating through a posterolateral defect in the diaphragm into the thorax. No other bowel loops were seen to be herniating through the defect (Figure 2).

The child was treated for bronchiolitis and recovered well. He is asymptomatic at one year follow up. 


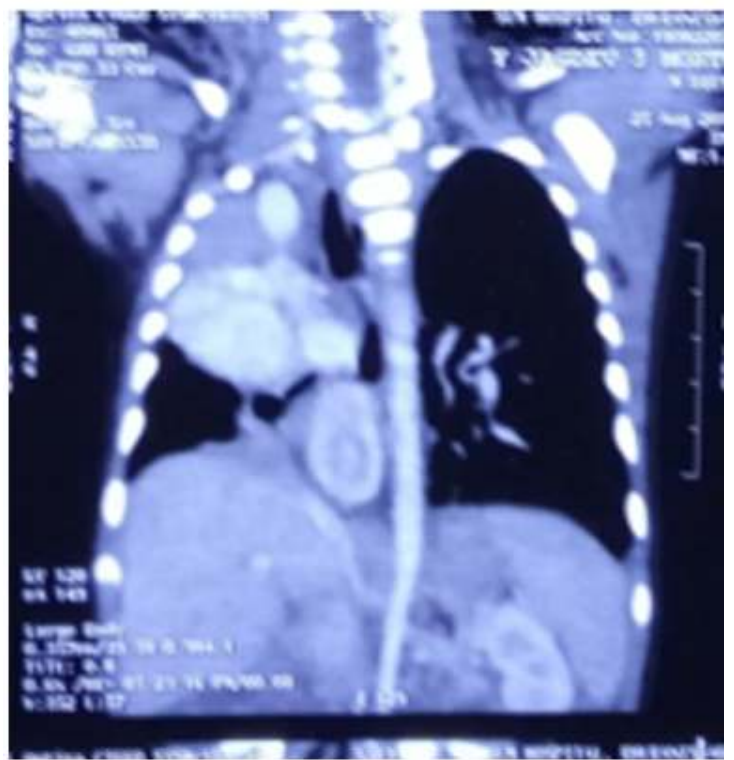

Figure 2: Contrast enhanced computed tomography of thorax

\section{Discussion}

The common side of intrathoracic ectopic kidney is the left which is twice as common as the right ${ }^{3}$. In our case the intrathoracic ectopic kidney was on the right side. Intrathoracic kidney is categorized into four groups according to its features ${ }^{4}$ :

1. Pure intrathoracic kidney with normal physiology.

2. Intrathoracic kidney with abnormal contour of dome of diaphragm.

3. Intrathoracic kidney with diaphragmatic hernia which is of two types congenital (Type A) or acquired (Type B).

4. Post-traumatic diaphragmatic tear and intrathoracic renal herniation.

The pure intrathoracic kidney is usually not associated with any other malformation. The condition remains asymptomatic and the diagnosis is incidental. Pulmonary symptoms are not so common and urinary symptoms are rarely encountered. The intrathoracic location of a kidney is commonly found to be associated with hypoplasia of the lower lobe of lungs ${ }^{5}$. This is unlike the present case where the hypoplasia is in the upper and middle lobes.

Plain radiographs usually confuse intrathoracic kidney with posterior mediastinal mass (like Bochdalek hernia), neurogenic mass or pulmonary sequestration. A contrast enhanced CT scan can easily diagnose the condition and can also be used as urography to know the functional status of the kidney. Nuclear imaging is very helpful in diagnosing it. Tc 99mDMSA and Tc 99mDTPA scintigraphy are needed to look for the structure and function of the ectopic kidney. However the most cost-effective, non-invasive and reliable method for screening is ultrasonography ${ }^{6}$. The renal vessels and the ureter goes in and out from the pleural cavity through the foramen of Bochdalek respectively.

The other types of intrathoracic kidneys associated with defect in the diaphragm usually have respiratory symptoms and failure to thrive. These children require investigation and further treatment by surgery. As the patient described here had both features of respiratory infection and failure to thrive we referred him to a paediatric surgeon since we suspected a defect in the right diaphragm.

Earlier research had concluded that some predisposing factors like maternal vitamin A or folic acid deficiency, radiation exposure, infectious agents during fetal period, teratogens, trisomy 18 and 21 lead to the development of renal ectopia 7 . The embryogenesis of this anomaly is explained by delayed involution of the mesonephros which leads to more cranial migration of the metanephros ${ }^{8}$.

\section{References}

1. Campbell MF. Renal ectopy. Journal of Urology 1930; 24(2):187-98. https://doi.org/10.1016/S00225347(17)72 892-3

2. Chong SL, Chao SM. An unusual case of mediastinal mass- A case report and literature review of intrathoracic kidney. Proceedings of Singapore Healthcare 2012; 21(2):144-50.

https://doi.org/10.1177/201010581202100 209

3. Sarac M, Bakal U, Tartar T, Canpolat S, Kara A, Kazez A. Bochdalek hernia \& intrathoracic ectopic kidney: Presentation of two case reports \& review of the literature. Nigerian Journal of Clinical Practice 2018; 21(5):681-6.

https://doi.org/10.4103/njcp.njcp_217_17 PMid: 29735873

4. Pfister-Goedeke L, Brunier E. Intrathoracic kidney in childhood with special reference to secondary renal transport in Bochdaleks hernia (Article in German). Helvetica Paediatrica Acta 1979; 34(4):345-57.

5. Maduekwe E, Weinberg B, Samaan B, Sheferaw E, Suntharos P. Right thoracic ectopic kidney in a child with breathing difficulties - sonographic diagnosis. Journal of Clinical Ultrasound 2011; 39(2):108-10. doi:10.1002/jcu.20716. 
https://doi.org/10.1002/jcu.20716

PMid: 20564312

6. Chang PL, Mrazek-Pugh B, Blumenfeld YJ. Prenatal diagnosis of cross fused renal ectopia: Does colour Doppler \& 3dimensional sonography help? Journal of Ultrasound in Medicine 2011; 30(4): 57880.

https://doi.org/10.7863/jum.2011.30.4.578 PMid: 21460160

7. Magak $\mathrm{P}$, King $\mathrm{CH}$, Ireri $\mathrm{E}$, Kadzo $\mathrm{H}$, Ouma JH, Muchiri EM. High prevalence of ectopic kidney in Coast province, Kenya. Tropical Medicine and International Health 2004; 9(5): 595-600. https://doi.org/10.1111/j.13653156.2004.0

1228.x

PMid: 15117304

8. Dingeldein MW, Kane D, Kim AW, Kabre $\mathrm{R}$, Pescitelli $\mathrm{Jr}$, Holterman $\mathrm{MJ}$, et al. Bilateral intrathoracic kidneys and adrenal glands associated with posterior congenital diaphragmatic hernias. Annals of Thoracic Surgery 2008; 86:651-4.

https://doi.org/10.1016/j.athoracsur.2008.0 2.036

PMid: 18640354 